\title{
Yenidoğanda Uzamış Sarılığın Nadir ve Önemli Bir Sebebi: infantil Hipertrofik Pilor Stenozu
}

A Rare and Significant Cause of Newborn Prolonged Jaundice:

Infantile Hypertrophic Pyloric Stenosis Muhammet Mesut Nezir Engin', Aybars Özkan², Önder Kilıçaslan', Fatih Kaya', Ramazan Cahit Temizkan', Kenan Kocabay'

'Düzce Üniversitesi Tıp Fakültesi Çocuk Sağlığı ve Hastalıkları A.D., DÜZCE

${ }^{2}$ Düzce Üniversitesi Tıp Fakültesi Çocuk Cerrahisi A.D., DÜZCE

Yazışma Adresi / Correspondence:

Muhammet Mesut Nezir ENGiN

Düzce Üniversitesi Tıp Fakültesi Çocuk Sağığı ve Hastalıkları A.D., DÜZCE

$\mathrm{T}: \mathbf{+ 9 0} 5426378810 \quad$ E-mail: doktormesut@hotmail.com

Geliş Tarihi / Received : 20.04.2018 Kabul Tarihi / Accepted : 11.10.2018

Bu çalışma 54. Türk Pediatri Kongresi 6-10 Mayıs 2018' de KKTC de sunuldu

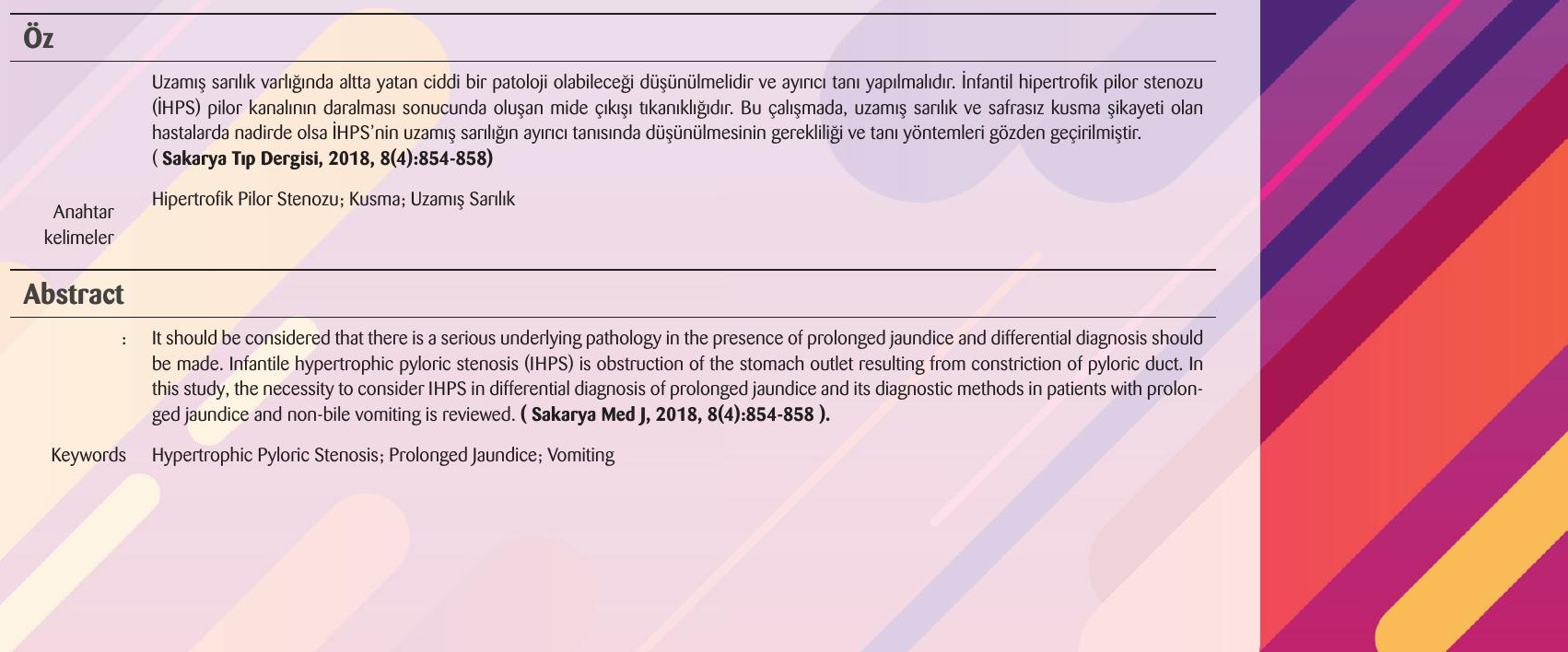






Sakarya TIp Dergis

GiN ve Ark.

İnfantil hipertrofik pilor stenozu (IHPS), pilorun düz kas liflerinin hiperplazisiyle pilor kanalının daralması sonucunda oluşan mide çıkışı tıkanıklığıdır. ${ }^{4}$ Yaşamının ilk ayı içindeki bebeklerde mide çıkışı darlığının en sık nedeni iHPS'dir. Hastalık 3-6 haftalık bebeklerde sayısı giderek artan fışkırı şekilde ve safrasız kusma ile kendini gösterir. Tanı konulamayan vakalarda dehidratasyon, ciddi beslenme bozukluğu ve asit-baz dengesizliğe seyreder, ihmal edilmesi halinde ölümle sonuçlanabilir. Yapılan çalışmalarda erkek çocuklarda kızlara göre 4 kat daha sık görülmektedir. Tanı sıklıkla yalnız öykü ve dikkatli fizik muayene ile konabilir, ultrasonografi (USG) ve kontrastlı pasaj filmler ile de tanı konabilmektedir. Cerrahi tedavide en yaygın olarak 1912'de Ramstedt tarafından tanımlanan ekstramukozal pyloromyotomi ameliyatı uygulanmaktadır. ${ }^{5}$

Bu çalışmada, uzamış sarılık ve safrasız kusma şikayeti olan hastalarda nadirde olsa iHPS'nin uzamış sarııı̆ın ayıııcı tanııında düşünülmesinin gerekliliği ve tanı yöntemleri gözden geçirilmiştir.

\section{Olgu Sunumu}

Otuz üç günlük erkek bebek uzamış sarılık ve kusma şikayetiyle dış merkeze başvurmuş, sonrasında tarafımıza yönlendirilmiş. Hastanın öyküsünden 38. gestasyonel haftada normal doğum ile 3185 gr ağırlığında doğduğu ve 33 günlük sürede başka bir sağlık problemi bulunmadığı öğrenildi. Aile öyküsünde annenin iki tane abortusu mevcuttu. Hastanın vücut ağırlığı 4550 gr (50-90p), boy $56 \mathrm{~cm}(50-90 p)$, baş çevresi $37 \mathrm{~cm}$ (50p), vücut ısısı $36,7^{\circ} \mathrm{C}$, kan basıncı 88/52 mmHg, nabız 137/dakika, solunum sayısı 39/dakika ve pulse oksimetre ile oksijen saturasyonu \% 96 saptandı. Fizik muayenesinde hastanın bilinci açık, cildi batına kadar ikterik görünümde, gözler çökük ve sağ kadranda umblikus hizasında $2 \times 1 \mathrm{~cm}$ ebatında kitle belirtisi vardı. Olive belirtisi olabileceği düşünüldü. Diğer sistem muayeneleri doğaldı. Hasta takip ve tedavi amaçlı pediatri servisine yatıııldı. Yatışında bakılan tetkiklerinde total bilirubin $10,8 \mathrm{mg} / \mathrm{dl}$, direkt bilirubin $0,8 \mathrm{mg} / \mathrm{dL}$, hemoglobin 10,3 $\mathrm{g} / \mathrm{dL}$ olarak saptandı. Alanin amino transferaz (ALT), aspartat aminotransferaz (AST) , tiroid bezini uyarıcı hormon (TSH), üre, BUN, kreatinin ve elektrolit değerleri normal sınırlardaydı. Ayakta direk batın grafisinde (ADBG) geniş ve dilate mide görüldü (Resim 1). Pilor stenozu yönünden çekilen oral kontrastlı ADBG'sinde "caterpillar sign" görüldü (Resim 2). Hastanın abdomen USG'sinde pilor düzeyinde duvar kalınlaşması mevcuttu, pilor transvers çapı $7,5 \mathrm{~mm}$, longitudinal uzunluğu 19 mm olarak ölçüldü. Ultrasonografi incelemesi sırasında pilordan sıvı geçişi saptanmadı. Hastaya iHPS tanısı konularak Ramstedt piloromyotomi operasyonu yapıldı (Resim 3). Altı saat sonra oral beslenmeye başlandı. Kusmaları önemli derecede azalan hasta önerilerle taburcu edildi. Hastanın ameliyat sonrasında 5.gününde poliklinik kontrolünde kontrol ADBG'si normal olarak, total bilirubin $3,19 \mathrm{mg} / \mathrm{dL}$ ve direkt bilirubin $0,58 \mathrm{mg} / \mathrm{dL}$, 12 .gününde total bilirubin $1,96 \mathrm{mg} / \mathrm{dL}$ ve direkt bilirubin $0,42 \mathrm{mg} / \mathrm{dL}$ olarak saptandı (Resim 4). Hastamı Gilbert sendromu yönünden takibe alınd. Hasta ebeveynlerinden onam alınmıştır. 


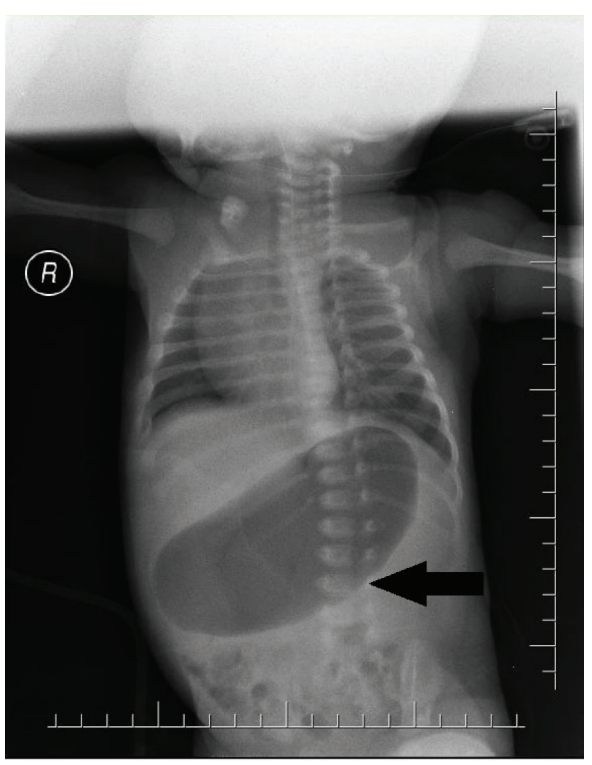

Resim 1: Hastanın ayakta direk batın grafisinde (ADBG) görülen "geniş ve dilate mide" görüntüsü

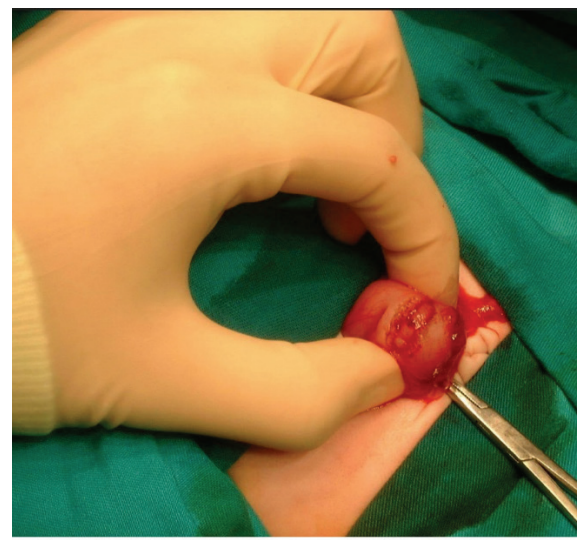

Resim 3: Hipertrofik pilorun ameliyat esnasında görünümü



Resim 2: Hastanın ayakta direk batın grafisinde (ADBG) görülen "caterpillar sign" bulgusu



Resim 4: Ameliyat sonrasında çekilen, normal olarak değerlendirilen ayakta direk batın grafisi (ADBG)

\section{Tartışma}

İnfantil hipertrofik pilor stenozu bazen uzamış sarılıkla bulgu verebilir. ${ }^{6}$ Lippert'in yaptığı olgu sunumunda 17 günlük bebek şiddetli uzamış sarılıkla başvurmuş, kusma ve pilor stenozu bulguları görülmemiştir. Etyolojik değerlendirme yapılırken görüntüleme yöntemleri sonrasında iHPS tanısı konularak pyloromyotomi yapıımıştır, sonrasında sarılık gerilemiştir. ${ }^{7}$ Literatüre baktığımızda Trioche ve ark.'larının ve Saz ve ark'larının yaptıkları olgu sunumlarında pilor stenozu ile ilgili görülen uzamış sarılığın Gilbert sendromunun erken belirtisi olabileceği düşünülmüştür. ${ }^{8-9}$ Bizim hastamızda safrasız kusma ve uzamış sarılık bulguları mevcuttu, ameliyat sonrası şikayetleri gerileyen hasta Gilbert sendromu yönünden takibe alındı. 
Sakarya TIp Dergisi 2018;8(4):854-858

Literatüre baktığımızda yenidoğanda iHPS durumunda görülen uzamış sarılık vakaları Gilbert sendromu olarak düşünülmüş, oluşum mekanizması sadece üridil difosfo glukronil transferaz (UDPGT) enzim eksikliğine bağlanmıştı..$^{8-9}$ Biz iHPS durumunda oluşan uzamış sarılığı iki farklı mekanizmaya bağlı olabileceğini düşünmekteyiz. ilk olarak midede oluşan tıkanıkık sonrası enterohepatik sirkülasyonun azalmasıyla barsak duvarının bakterilerle kolonizasyonu gecikir. Bu durum direkt bilirubinin sterkobiline dönüşümünü azaltır. Yenidoğanda fizyolojik olarak enterik mukozal betaglukuronidaz enziminin fazla olması nedeniyle indirekt hiperbilirubinemi gelişir. ikinci olarak, uzun süren açlığın UDPGT enzim eksikliği oluşturarak indirekt hiperbilirubinemiye neden olduğu öngörülmektedir.

Uzamış sarılıkla ilgili yapılan çalışmalara bakıldığında Bilgin ve ark.'larının 2017 yılında 100 olguda yaptığı çalışmada \%78'inin etyolojisi saptanamazken, \%14'ünde idrar yolu enfeksiyonu, \%3'ünde Glukoz-6-fosfat dehidrogenaz eksikliği, \%3'ünde konjenital hipotiroidi ve \%2'sinde Rh uygunsuzluğu bulunmuştur ve pilor stenozu saptanmamıştır. ${ }^{10}$ Tuygun ve ark.'larının 2002 yilında Ankara'da uzamış sarııkla ilgili yaptıkları çalışmada 231 olgunun \%63,2'sinde etyoloji saptanamazken, $\% 8,2$ 'sinde $A B O$ uygunsuzluğu, \%7,4'ünde idrar yolu enfeksiyonu, \%3,9'unda Rh uygunsuzluğu ve diğer sebepler bulunurken pilor stenozu saptanmamıştır. ${ }^{11}$ Ökten ve ark.'larının 1992 yilında Trabzon'da 121 olguda uzamış sarılıkla ilgili yaptıkları çalışmada 1 olguda pilor stenozu saptanmıştır. ${ }^{12}$ Literatüre baktığımızda uzamış sarılık olgularında çoğunlukla etyoloji saptanamamıştır, iHPS'de nadir olarak görülmüştür.

Etyolojik değerlendirmede iHPS düşünüldüğünde tanı aşamasında USG'de duvar kalınlığının > 4 mm ve pilor kanal uzunluğunun $>16$ mm olması IHPS varlığı lehinde değerlendirilir.5 Oral kontrast madde sonrası çekilen ADBG'de midede hiperperistaltizm, pilor kanalında uzama ve daralma (string sign), antral "diş" (teeth) veya "omuz" (shouldering) bulgusu, antral "gaga” (beak sign) bulgusu, pilor kanalında "çift yol” (double track) bulgusu, duodenal bulbusta "şemsiye” (umbrella sign) bulgusu tanı koydurucu bulgulardır. ${ }^{13}$ Pilordaki darlığa karşı gastrik kasıımaların ADBG'de oluşturduğu görünüme "tırtıl işareti”' (caterpillar sign) denir. Bizim hastamızın oral kontrastlı ADBG'sinde "caterpillar sign “ görüldü, Abdomen USG'sinde pilor transvers çapı 7,5 mm, longitudinal uzunluğu 19 mm olarak ölçüldü (Resim 2).

Sonuç olarak yenidoğan döneminde etyolojisi saptanamayan uzamış sarılık varlığında, kusma ve beslenme bozukluğu eşlik ediyorsa çok nadir gözükse de iHPS mutlaka akılda tutulmalıdır. Enterohepatik sirkülasyonun azalmasına bağlı oluşan etkilerle indirekt hiperbilirubinemi görülür. IHPS tanısında spesifik USG ve direkt grafi bulguları vardır. 
1. Mishra $S$, Agarwal $R$, Deorari AK, Pauk VK. Jaundice in the newborns. Indian Jpediatr 2008;75:157-163

2. Yanagi T, Nakahara S, Maruo Y. Bilirubin Uridine Diphosphate-glucuronosyltransferase Polymorphism as a Risk Factor for Prolonged Hyperbilirubinemia in Japanese Preterm Infants. J Pediatr 2017;190:159-62

3. Engin MMN, Kilıçaslan Ö, Kaya F, Kocabay K. Yenidoğanda nadir görülen patolojik sarılık vakasi; Herediter Sferositozlu Aile. 61. Türkiye Milli Pediatri Kongresi. 2017/ Antalya.

4. Ndongo R, Tolefac PN, Tambo FFM, Abanda MH, Ngowe MN, Fola O et al. Infantile hypertrophic pyloric stenosis: a 4 year experience from two tertiary care centres in Cameroon. BMC Res Notes 2018:11:33.

5. Aydoğdu B, Sander S, Demirali O, Güvenç Ü, Başdaş CB, Mahmut Z ve ark. İnfantil Hipertrofik Pilor Stenozu: Çocuklarda En Sık Safrasız Kusma Nedeni. JOPP Derg 2012;4(2):69-73

6. Labrune $P$, Myara A, Huguet $P$, Trivin F, Odievre M. Jaundice with hypertrophic pyloric stenosis: A possible early manifestation of Gilbert syndrome. J Pediatr 1989;115:93 - 95

7. Lippert MM, Pyloric stenosis presenting as severe prolonged jaundice. A case report. S Afr Med J 1986 Mar 29;69(7):446-7.
8. Trioche P. Chalas J. Francoual J, Capel L, Lindenbaum A Odievre M et al. Jaundice with hypertrophic pyloric stenosis as an early manifestation of Gilbert syndrome. Arch Dis Child 1999;81:301-303

9. Saz EU, YIldız B, Alpman A, Onay H, Özkınay F. A case of jaundice associated with hypertrophic pyloric stenosis carrying UGT1A1 polymorphism. Journal of Medicine and Medical Sciences 2010;1(5):141-143

10. Bilgin BS, Gönülal D, Ünal S. Uzamıs Sarlıkıı Bebeklerin Etiyolojik, Klinik ve Laboratuvar Bulgularının Değerlendirilmesi. Türkiye Çocuk Hastalıklar Dergisi 2017, DOI: 10.12956/tjpd.2017.320

11. Tuygun N, Tiras Ü, Sıklar Z, Erdeve Ö, Tanyer G, Dallar Y. Yenidoğan uzamıs sarilığının etyolojik yönden değerlendirilmesi ve anne sütü sarllı̆̆ Türk Pediatri Arşivi 2002;37:138-143

12. Ökten A, Mocan H, Erduran E, Gedik Y. Uzamış sarilığı olan 121 bebekte prospektif bir çalıșma. OMÜ Tip Dergisi 1992:9(2):112-116

13. Görmez A, Haliloğlu M. Pediatrik Abdomende Kontrastlı Radyografi. Trd Sem 2017; 5: 146-156 $\pi$
$D$
$\prec$
$z$
$D$
$\pi$
$=$
$D$
$D$

Sakarya Tıp Dergisi

2018;8(4):854-858

ENGiN ve Ark.

Yenidoğanda Uzamış Sarılığın Nadir ve Önemli Bir Sebebi.

infantil Hipertrofik Pilor Stenozu 